\title{
CARACTERÍSTICAS DE PROFESSORES DE UM CAMPUS DA REDE FEDERAL: ANÁLISE DE ASPECTOS PESSOAIS, PROFISSIONAIS E SOCIAIS
}

\author{
Adriana Vieira dos Santos, ${ }^{*}$ Manuel Alves de Sousa Junior \\ E-mail: dricaquimica@gmail.com \\ Instituto Federal de Educação, Ciência e Tecnologia da Bahia, Campus Lauro de Freitas, \\ Brasil
}

DOI: $10.15628 /$ rbept.2020.9277

Artigo submetido em xx/2019 e aceito em xx/2019

\begin{abstract}
RESUMO
O perfil do professor é uma temática oportuna, inclusive tratando-se da figura do docente da educação básica do ensino profissional e tecnológico quando colocada em discussão. É salutar conhecer a identidade, cultura e aspectos pessoais e sociais desse profissional, já que ele é um ator protagonista no processo de ensino e aprendizagem na prática educativa. Este estudo, realizado em 2018, é descritivo com abordagem quantitativa sendo a amostra constituída de 58 professores que atuam em diversos níveis de ensino em um dos campus do Instituto Federal da Bahia (IFBA). Foram avaliados aspectos relacionados à naturalidade, gênero, regime de trabalho, religião, entre outros da amostra. Considera-se que estes aspectos no qual 0 docente se constitui podem influenciar diretamente no seu fazer pedagógico e que pode se tratar de dados para a gestão que podem refletir na qualidade do ensino.
\end{abstract}

Palavras-Chave: Perfil de Professores. Rede Federal. Ensino Profissional e Tecnológico.

\section{CHARACTERISTICS OF TEACHERS OF A FEDERAL NETWORK CAMPUS: ANALYSIS OF PERSONAL, PROFESSIONAL AND SOCIAL ASPECTS}

\begin{abstract}
The teacher's profile is a timely theme, including the figure of the teacher of basic education in vocational and technological education when put into discussion. It is healthy to know the identity, culture and personal and social aspects of this professional, since he is a protagonist actor in the teaching and learning process in educational practice. This study, conducted in 2018 , is descriptive with a quantitative approach. The sample consisted of 58 teachers who work at different levels of education in one of the campuses of the Federal Institute of Bahia (IFBA). Aspects related to place of birth, gender, work regime, religion, among others in the sample were evaluated. It is considered that these aspects in which the teacher is constituted can directly influence their pedagogical practice and that they may be data for management that may reflect on the quality of teaching.
\end{abstract}

Keywords: Teacher Profile. Federal Network. Vocational and Technological Education. 


\section{INTRODUÇÃO}

O perfil do professor é uma temática totalmente oportuna e em voga desde os anos 1990, quando a figura do professor da educação básica foi colocada em discussão. Se por um lado o docente é responsável pela consolidação de novos paradigmas científicos, culturais e éticos, por outro lado esse profissional é geralmente desvalorizado na sociedade (NÓVOA, 1999).

Considerar a subjetividade do professor pode exigir da instituição o exercício de considerar o professor-pessoa e não somente o professorprofissional, já que o docente não pode ser mais visto apenas como aquele que repassa conteúdos. O perfil do professor ajudará a instituição a investir na sua formação continuada e na consequente melhoria da qualidade do ensino.

Neste estudo foram reunidas características de uma amostra da rede federal com o objetivo de representar a realidade desse grupo, considerando que cada contexto educacional é único e que faltam dados que caracterizem o perfil de profissionais da educação, tais como os professores. Neste artigo abordamos características dos professores em relação a diversos aspectos como sexo, profissão, religião, faixa etária, estado civil, renda familiar etc.

\subsection{PROFISSÃO DOCENTE}

O professor é um dos principais atores no processo de construção do conhecimento. É um ser que se constrói a partir das relações com o meio social no qual está inserido, portanto também é cheio de expectativas e angústias, e por isso não deve soar estranho a necessidade de se pesquisar seu perfil social, cultural e até econômico (GATTI, 2003).

Geralmente, a instituição se preocupa em conhecer a formação do professor, pois a LDB (Lei de Diretrizes e Bases) preconiza em seu artigo 67 o aperfeiçoamento profissional continuado, mas é importante se considerar o professor como um todo, considerar valores e atitudes, ou seja, as formas do que ele pode levar da vida para a escola (BRASIL, 1996).

Segundo Goodson (1995) a identidade e cultura do professor tem impacto sobre a sua prática educativa, sendo assim a formação que o professor propiciará aos seus alunos é reflexo das suas vivências, da sua visão de mundo e dos seus saberes. 


\subsection{A RELIGIÃO E A ESCOLA}

O Estado é livre e democrático de direito. Deve tratar todos os cidadãos de forma igualitária, livres e iguais em direitos e dignidade, o que se estende para o contexto da religião, visto que é um país laico (MAK, 2014).

As religiões são verdadeiras instituições em torno da ideia de espírito e deuses e referem-se a sistemas de cultos e crenças diversas que os fiéis adotam e entendem ser meios que conduzem à felicidade e satisfação. Borges e colaboradores (2015), continuam essa análise afirmando que o propósito da religião é promover uma estrutura onde se possa desenvolver uma consciência espiritual.

A escola não é um fenômeno isolado no contexto sociocultural, econômico, político e religioso. A religiosidade faz parte da cultura brasileira e não tem como impedir que adentre os portões das escolas com docentes, discentes e funcionários (MAK, 2014).

Valente (2014) analisa a socialização religiosa na escola, defende que muitas são as formas de manifestação de crenças, adereços, amuletos, roupas e acessórios que ocorrem mesmo em escolas sem oferta de disciplinas de caráter religioso.

O dicionário Aurélio (FERREIRA, 2010) traz o conceito de religiosidade como sendo a qualidade de religioso, a disposição ou tendência para a religião ou coisas sagradas. O dicionário Houaiss complementa com "conjunto de escrúpulos religiosos ou de valores éticos que apresentam certo teor religioso" (HOUAISS; VILLAR, 2009).

Historicamente de maioria Católica, o Brasil, seus estados e municípios possuem muitos feriados e festividades religiosas passadas de geração em geração e por isso enraizadas na cultura popular, mesmo que inconscientemente. Festas e comemorações escolares como Páscoa, São João e Natal são exemplos de cunho religioso, mas que já são afirmadas e reafirmadas na população como um todo, independente da religião praticada (MAK, 2014).

\footnotetext{
Para muitos agentes que atuam na escola, o campo religioso pode ser confundido com sua atuação profissional e o poder simbólico que ele pode exercer sobre 0 alunado provavelmente passa despercebido, pois para muitos educadores isso é imperceptível, o seu hábito já traz essa disposição, o que torna a religião algo naturalizado (MAK, 2014, p. 36).
}

Mak (2014), ainda afirma que a religião é algo que auxilia na construção da realidade, muitas vezes conforta e dá sentido à vida das pessoas, além de poder ajudar com vários questionamentos e se tornar essencial no contexto de uma sociedade contraditória, onde riqueza e pobreza vivem lado a lado. A autora complementa que dizendo que a religião traz o conforto necessário para uma camada populacional desprivilegiada. 
A Constituição brasileira de 1988 determina em seu artigo 210, parágrafo primeiro, que "O ensino religioso, de matrícula facultativa, constituirá disciplina dos horários normais das escolas públicas de ensino fundamental" e a lei n. ${ }^{\circ}$ 9475, de 22 de julho de 1997, deu nova redação ao art. 33 da Lei n. .9394 de 20 de dezembro de 1996 e estabelece que "O ensino religioso, de matrícula facultativa, é parte integrante da formação básica do cidadão e constitui disciplina dos horários normais das escolas públicas de ensino fundamental, assegurado o respeito à diversidade cultural religiosa do Brasil, vedadas quaisquer formas de proselitismo" sendo assim o ensino religioso tem que conduzir os estudantes a valores do bem, da honestidade etc (BRASIL, 1988; BRASIL, 1996).

Sobre o ensino de religião nas escolas a lei estabelece que a matrícula é facultativa e deveria ser voltada para o ensino de várias religiões, e não para o ensino de uma única religião, considerando a perspectiva laica do país (AZEVEDO, 2016).

A formação de professores para o ensino religioso enfrenta alguns desafios, como por exemplo, o fato do docente não possuir diploma de licenciatura específico em religião, abordar todas as religiões de um modo geral e sem doutrinação, entre outros. Ademais, "o docente deve priorizar a formação da pessoa do professor, como um mediador, um ser-em-relação, um ser social inserido em um contexto sócio-político-cultural e religioso, um ser em busca do transcendente e com capacidades a serem desenvolvidas" (SILVA; SOARES, 2010).

A educação no Brasil é compreendida como um direito de todos e dever do Estado e da família em comum acordo com a sociedade, de modo a preservar a igualdade de condições e o respeito à pluralidade de ideias. A educação no país está organizada em Básica e Superior. A educação básica tem por objetivo favorecer o desenvolvimento da capacidade de aprendizagem, tendo como meios básicos o pleno domínio da leitura, da escrita e cálculo; bem como a compreensão do ambiente cultural e social, do sistema político, da tecnologia, das artes e dos valores em que se fundamenta a sociedade brasileira; a aquisição de conhecimentos e habilidades, conforme o Art. 32.ำ, Lei 9394/96. Os docentes, sujeitos da pesquisa, atuam na educação básica e no ensino superior em um campus do IFBA (BRASIL, 1996).

Atualmente, sobretudo nos últimos anos, a formação do professor e aspectos relacionados sobre o seu perfil estão em voga. A preocupação em torno dessa temática é um dos grandes desafios que são impostos à educação por conta dos avanços tecnológicos e científicos ocorridos em nossa sociedade e que tem provocado mudanças no desenvolvimento intelectual, social e cultural afetando diretamente todos os envolvidos no processo educativo, conforme afirma SANTOS (2007). A autora ainda acrescenta que o homem, de um modo geral, está distante de sua espiritualidade, o que pode deixar em xeque valores pessoais e sociais.

Sampaio em 2004 (p. 30) já afirmava que “(...) estamos vivendo uma crise global profunda, onde o vazio existencial e afetivo favorece a miséria, a violência, a corrupção, o medo, resultado de fragilidade das relações e dos 
valores humanos". Essa característica está mais viva nos dias atuais, ainda mais com o advento das redes sociais.

\section{OBJETIVOS}

Este artigo permite reconhecer parcialmente quem são os docentes de um dos campus do IFBA considerando o universo micro de estudo, mas também pode-se fazer uma projeção macro dos docentes da rede federal. Poderia se pensar que o universo dessa pesquisa seria de professores dedicados exclusivamente ao IFBA mas não é este o caso. Aqui foram analisadas a amostra de professores que envolve os regimes de dedicação exclusiva, 40h e $20 \mathrm{~h}$ e ainda os denominados inapropriadamente como substitutos (ou seja, essa fatia da amostra trabalha em outros lugares além do instituto federal mencionado) já que ao invés de substituírem o lugar vago de um professor são chamados para complementarem carga horária de trabalho docente.

\section{JUSTIFICATIVA}

O presente trabalho justifica-se para esclarecer e trazer à comunidade acadêmica (gestão, docentes, discentes e demais servidores) os dados inexistentes sobre o perfil dos docentes deste campus do IFBA e esta pesquisa pode servir para futuros estudos em outros campus gerando assim um banco de dados com informações que possam subsidiar os professores e as próprias instituições no que tange à formação continuada, procurando incluir temas de interesse geral e especifico, com a intenção de proporcionar uma melhora significativa no processo ensino-aprendizagem e profissionalização dos sujeitos pesquisados, os professores.

\section{METODOLOGIA}

Foram utilizadas abordagens qualitativa e quantitativa de pesquisa com uso de questionário e escuta dos professores no momento do preenchimento do questionário. Como a pesquisa envolveu a investigação de seres humanos, o projeto foi encaminhado ao Comitê de Ética em Pesquisa do IFBA e foi aprovado sob o parecer de $n^{\circ} 2.407 .237$ e CAAE $n^{\circ}$ 78925617.0.0000.5031, sendo então liberada a coleta de respostas aos questionários.

O questionário de pesquisa aqui utilizado foi adaptado do modelo UNESCO (2004) para atender o universo de 70 professores de um campus do Instituto Federal da Bahia. Foi realizado um teste piloto, ou seja, a aplicação desse instrumento de pesquisa para um conjunto de professores de modo a validá-lo, principalmente na coerência, entendimento e tempo. 
De acordo com o glossário da plataforma Nilo Peçanha ${ }^{1}$, o termo professor refere-se ao número de professores da rede Federal da Educação Profissional, Científica e Tecnológica reunindo servidores efetivos e substitutos/temporários, por isso neste trabalho a nomenclatura professor será usada indistintamente. O questionário, de questões objetivas e subjetivas, foi aplicado a 58 professores considerando que foram excluídos da amostra os docentes afastados. Esse trabalho apresenta apenas os resultados do estudo considerando aspectos relacionados à naturalidade, gênero, regime de trabalho, religião, entre outros dos participantes da pesquisa. Os dados foram coletados nos meses de novembro e dezembro de 2017.

\section{$5 \quad$ RESULTADOS E DISCUSSÕES}

O campus do IFBA estudado possui um total de 70 docentes, sendo que destes, 6 estavam afastados de suas atividades laborais por motivo de saúde, afastados para estudos ou ainda afastado de suas atividades docentes por causa de cargo na reitoria no período de coleta dos dados. Do total de docentes ativos $(n=64)$, cerca de $90,63 \%(n=58)$ responderam o questionário. A minoria de $9,37 \%(n=6)$ se recusou ou não teve tempo disponível para responder o questionário. O instrumento possuia teor social, cultural, religioso, além de dados pessoais e profissionais, incluindo os acadêmicos.

Com relação à naturalidade, pode-se observar na figura 1, que apesar do referido campus ficar no estado da Bahia, existem diversos docentes naturais de outros estados e mesmo de outro país com $1,72 \%(n=1)$ em Pernambuco, $1,72 \%(n=1)$ outra nacionalidade, 3,44\% $(n=2)$ de Sergipe, $5,18 \%(n=3)$ de Minas Gerais, 5,18\% $(n=3)$ são naturais do Rio de Janeiro, $8,62 \%(n=5)$ são naturais de São Paulo e a maioria dos entrevistados $74,14 \%(n=43)$ são naturais da Bahia. 


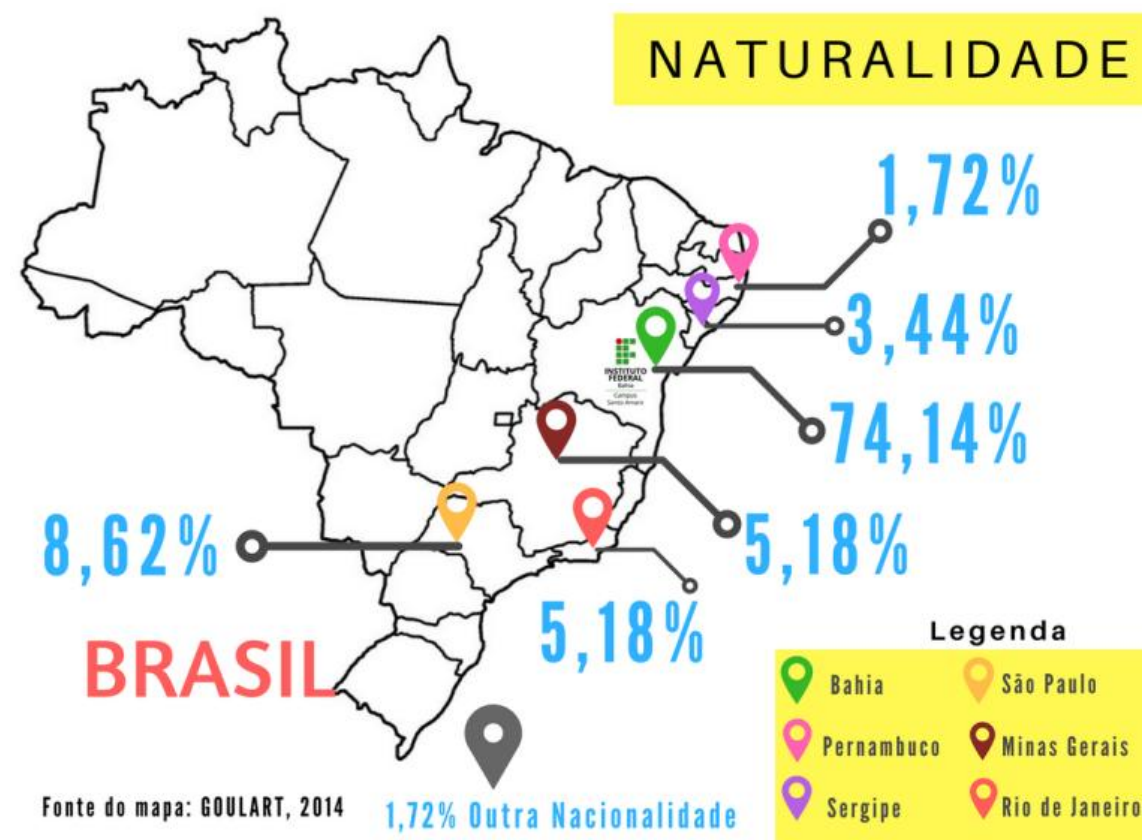

Figura 1. Mapa do Brasil com a naturalidade dos docentes entrevistados.

Fonte do Mapa: Goulart, 2014.

Do total de professores baianos $(74,14 \%)$, um total de $56,90 \%(n=33)$ são naturais de cidades da Região Metropolitana de Salvador, sendo 51,70\% ( $n=30)$ da capital, e 17,24\% $(n=10)$ são de outras cidades da Bahia. Apenas 5,18\% $(n=3)$ são naturais de cidades do Recôncavo Baiano, região do estado onde se localiza o campus sob análise. Nenhum docente é natural da cidade do campus.

Com relação ao gênero, os professores do referido campus do IFBA são $32,8 \%(n=19)$ composto de sexo feminino e $67,2 \%(n=39)$ do sexo masculino. Em comparação à pesquisa realizada pela UNESCO, percebe-se uma variação nesse quesito. A referida instituição fez uma entrevista com 5.000 professores da rede pública e privada nas 27 Unidades da Federação em 2004 e obteve $81,3 \%$ do sexo feminino e $18,7 \%$ do sexo masculino. Essa discrepância entre os resultados pode estar relacionado com a natureza dos cursos oferecidos pelo campus do IFBA, que geralmente possuem mais homens do que mulheres nessas áreas, como eletromecânica e informática. Seabra e Mattedi (2017) corroboram com esses dados, visto que encontraram $84,8 \%$ de ingressantes masculinos nos cursos de informática da Universidade Federal de Itajubá. Souza (2013) relata outros dados com prevalência feminina na Prova Brasil em 2011 com 69,5\%, no Censo dos Profissionais do Magistério em 2003 com 85,1\%, e no Censo Demográfico em 2010 com $51,03 \%$.

Um censo publicado pelo MEC/INEP em 2009 com os professores do país revela que a participação de homens no ensino é baixa nas séries iniciais e vai subindo gradativamente em cada etapa da educação até o ensino médio e chega a passar o número de mulheres no ensino profissional. Exatamente o que ocorre no campus do IFBA diagnosticado revelando um predomínio masculino entre os docentes. 
A Tabela 1 traz dados sobre a idade dos docentes, inclusive por sexo. Pode-se notar que a maioria dos docentes do campus com $36,21 \%(n=21)$ são homens na faixa etária de 36 a 45 anos. No total, essa mesma faixa etária é a mais predominante com $50 \%$. Na pesquisa realizada pela UNESCO (2004) a maioria dos docentes também tem de 36 a 45 anos, porém com predomínio de mulheres. Esse fato talvez seja justificado por algumas áreas de ensino no campus, que possuem tradicionalmente mais adesão masculina do que feminina, como por exemplo, segurança do trabalho, eletromecânica e informática.

TABELA 1 - Proporção de professores, por sexo, segundo a faixa etária

\begin{tabular}{|cccccccc}
\hline & \multicolumn{9}{c}{ Sexo } \\
Idade do Docente & \multicolumn{2}{c}{ Feminino } & \multicolumn{2}{c}{ Masculino } & \multicolumn{2}{c}{ Total } \\
& $\mathbf{n}$ & $\%$ & $\mathbf{n}$ & $\%$ & $\mathbf{n}$ & $\%$ \\
Até 25 anos & 0 & 0 & 0 & 0 & 0 & 0 \\
De 26 a 35 anos & 7 & 12,06 & 10 & 17,24 & 17 & 29,31 \\
De 36 a 45 anos & 8 & 13,79 & 21 & 36,21 & 29 & 50 \\
De 46 a 55 anos & 0 & 0 & 4 & 6,90 & 4 & 6,90 \\
Mais de 55 anos & 4 & 6,90 & 4 & 6,90 & 8 & 13,79 \\
\hline TOTAL & $\mathbf{1 9}$ & $\mathbf{3 2 , 7 5}$ & $\mathbf{3 9}$ & $\mathbf{6 7 , 2 5}$ & $\mathbf{5 8}$ & $\mathbf{1 0 0}$ \\
\hline
\end{tabular}

Fonte: Autores.

Com relação ao estado civil, $65,52 \%(n=38)$ são casados ou vivem juntos em união conjugal consensual, $18,97 \%(n=11)$ são solteiros, $12,06 \%$ $(n=7)$ são divorciados ou separados e apenas $3,45 \%(n=2)$ são viúvos. No universo de 5000 docentes pesquisados pela UNESCO (2004) a maioria também é casado ou vive junto com $83,4 \%$.

Um total de $70,69 \%(n=41)$ dos docentes atuam como principais provedores de renda de suas residências. Destes, $75,61 \%(n=31)$ são homens. Cerca de $41,37 \%(n=24)$ destinam de 81 a $100 \%$ dos rendimentos como contribuição familiar mensal. De acordo com os dados a UNESCO (2004), a maioria dos chefes de família também são homens com 72,7\%.

Do total de professores pesquisados, $79,3 \%(n=46)$ possuem 0 regime de trabalho de dedicação exclusiva, $3,5 \%(n=2)$ são 40 h efetivos sem dedicação exclusiva, $12 \%(n=7)$ são substitutos e $5,2 \%(n=3)$ são docentes $20 \mathrm{~h}$. Do total de professores efetivos $(88 \%, n=51)$, apenas $10,3 \%(n=6)$ dos docentes vieram de outros campi, os demais tomaram posse e entraram em exercício no próprio campus. A quantidade de docentes substitutos é regulamentada pela nota técnica $n^{\circ} 50$ de 2016 do Ministério da Educação e Cultura. 
Os docentes do campus pesquisado possuem uma média de 108 alunos por professor, com números variando entre 28 e 274 discentes. O número de turmas/professor varia de 3 a 9 . Os dados foram obtidos através dos dados de matrícula no setor responsável. Considerando a resolução de carga horária docente em vigor, estima-se que docentes com muitas turmas/alunos façam poucas atividades nas áreas de pesquisa e extensão.

\subsection{RELIGIOSIDADE X DOCENTES}

Com relação à religião, assim como no país laico que é o Brasil, várias religiões foram citadas na auto-declaração. Um total de 60,4\% ( $n=35)$ relataram ter alguma religião, enquanto $34,5 \%(n=20)$ declararam não ter religião e 5,2\% $(n=3)$ não responderam.

De acordo com a figura 2, a maioria dos professores religiosos disse ser da religião católica com $54,3 \%(n=19)$, seguida de espiritismo com $25,7 \%(n=9)$, protestantes com 8,6\% $(n=3)$. Igreja de Jesus Cristo dos Santos dos Últimos Dias (SUD), Wicca, Batista e Candomblé foram citadas por apenas $2,85 \%(n=1)$ para cada uma, como pode ser observado na Figura 2. No questionário essa pergunta foi subjetiva e então os docentes declararam suas religiões do modo mais confortável, desse modo, religiões evangélicas foram declaradas separadamente como protestante, batista e SUD.

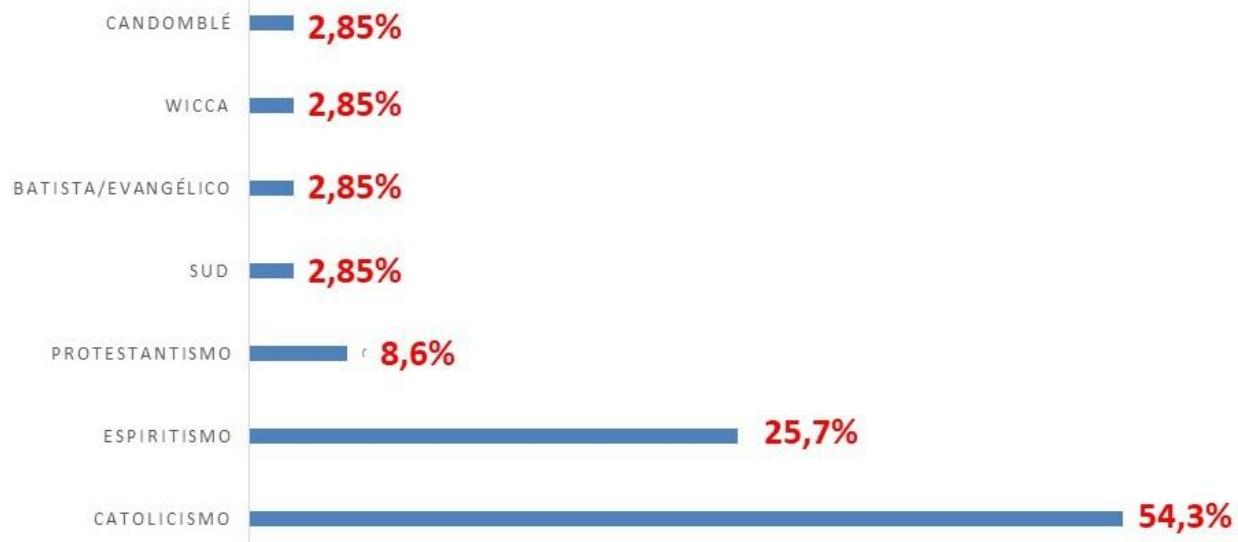

Figura 2 - Prevalência das religiões auto-declaradas dos docentes do campus do IFBA.

Fonte: Autores.

$\mathrm{Na}$ Bahia, de acordo com dados do IBGE (2012), a maioria da população é católica com $65 \%$. Os evangélicos somam $17 \%$, espíritas 1,3\% e os que não possuem religião perfazem $12 \%$. O número de docentes católicos do campus do IFBA ora analisado também é maioria e as porcentagens são próximas com as da Bahia, bem como os evangélicos. A discrepância 
encontra-se na quantidade de pessoas sem religião na Bahia com $12 \%$ pelos dados do IBGE e nos docentes do campus com 36,2\%.

No questionário, após perguntado sobre religião, o docente escreveu qual a religião e respondeu se é praticante ou não. Dos docentes religiosos (n $=35), 63 \%(n=22)$ são praticantes. O fato que chama atenção é que na religião mais predominante $(n=19$, catolicismo), a maioria com $63 \%(n=12)$ não são praticantes. Na segunda religião mais frequente, o espiritismo, 100\% dos docentes praticam.

Essa diferença é notória no trabalho de Borges e colaboradores (2015), no qual relatou $36 \%$ de docentes espíritas e $28 \%$ católicos, apenas 0 número de evangélicos, 4\%, fica próximo aos resultados de nossa pesquisa.

O professor, para Vieira e Placco (2011), não é agente neutro, e ao trabalhar com a cultura e ciências humanas, trabalha com possíveis valores que são escolhidos ou selecionados de modo geralmente consciente. E complementam dizendo que é consequência natural que o aluno seja influenciado de algum modo. O professor ajuda o estudante a estabelecer significados para as experiências que vive na sociedade.

Os docentes da área de humanas, inclusive pela natureza específica da área, devem discutir mais profundamente sobre o tema religião do que professores de outras áreas. Do total de docentes pesquisados, 17,24\% ( $\mathrm{n}=$ 10) são de humanas, nos quais apenas $40 \%$ têm religião. São $20 \%$ católicos e $20 \%$ espíritas, sendo que dos Católicos, metade são praticantes e os espíritas citados praticam.

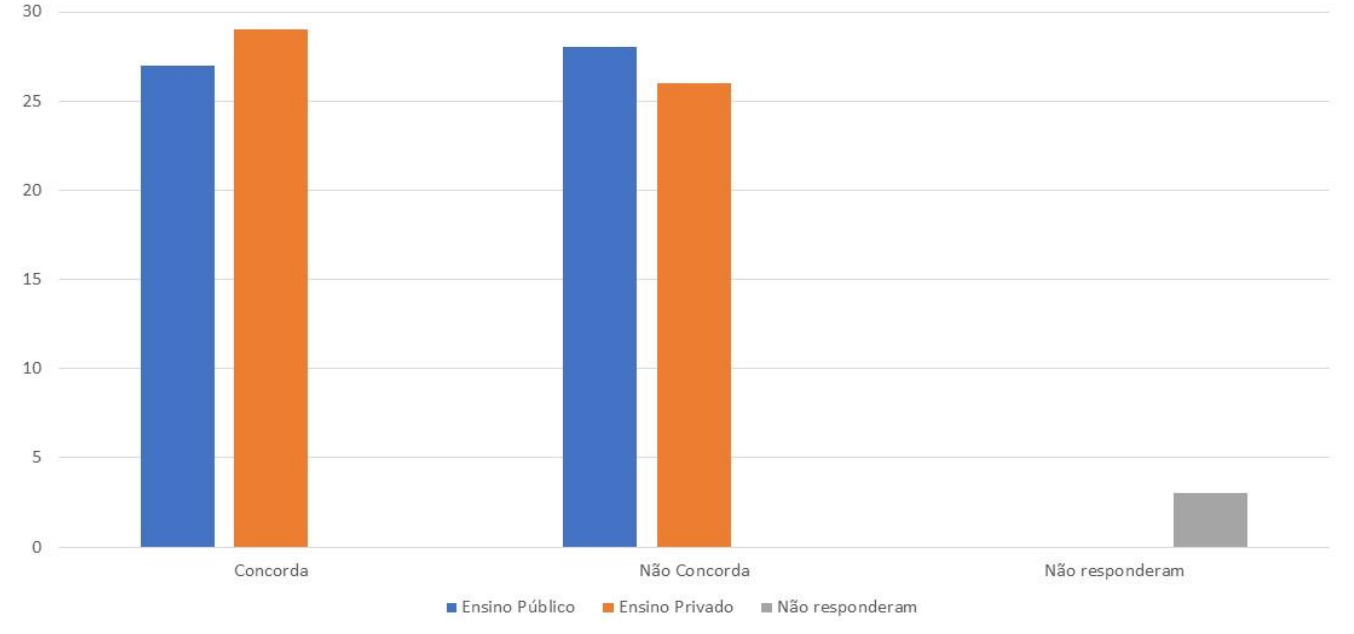

Figura 3 - Concordância dos docentes pela abordagem do tema religião na escola.

Fonte: Autores 
Os docentes foram perguntados se concordam com a abordagem do tema religião na escola, tanto no ensino público quanto no ensino privado. A questão permitia apenas responder se "sim" ou "não", sem espaço para justificativas. Na Figura 3 percebe-se que as respostas sobre a concordância ou não estão bem equilibradas. Com relação ao ensino público, 46,5\% ( $n=$ 27) concordam que o tema seja abordado na escola e no ensino privado os que concordam somam $50 \%(n=29)$. Um total de $5 \%(n=3)$ dos docentes não se sentiram confortáveis ou não possuem opinião formada sobre a temática. Um estudo da UNESCO (2004), realizado com 5000 docentes apresenta certa divergência com os resultados de nossa pesquisa, no qual os que concordam são $66,2 \%$ no ensino público e $55,1 \%$ no ensino privado. Este é um tema bastante polêmico para abordagem nas escolas, principalmente pelo fato da educação brasileira ser laica, de acordo com a carta magna de 1988.

Um ponto interessante é que, apesar da questão ser objetiva, alguns docentes fizeram questão de relatar que essa é uma temática polêmica e então precisaria ser discutido de como debater religião na escola. Nessa instituição onde os professores foram o foco da pesquisa, observou-se que alguns estudantes utilizam o horário de intervalo das aulas para realizarem cultos evangélicos. Outro docente relatou que concorda com a abordagem religiosa de forma ampla e sem foco em qualquer religião.

\subsection{INFLUÊNCIA E CONSTRUÇÃO PARA CARREIRA DOCENTE}

A grande maioria dos docentes, $82,75 \%(n=48)$, declarou haver outro membro da família com a profissão de professor. Os familiares mais citados foram cônjuge, seguido de irmãos e mãe. No universo docente pesquisado pela UNESCO (2004) a quantidade de docentes com familiares professores foi de $63,3 \%$.

TABELA 2 - Proporção de professores, segundo o nível de escolaridade dos pais.

\begin{tabular}{|ccccc} 
Nível de Escolaridade dos & \multicolumn{5}{c}{ Proporção } \\
Pais & $\mathbf{n}$ & $\%$ & $\mathbf{n}$ & Pai \\
Sem instrução & 1 & 1,72 & 3 & 5,18 \\
Fundamental incompleto & 12 & 20,69 & 13 & 22,41 \\
Fundamental completo & 6 & 10,35 & 7 & 12,07 \\
Ensino Médio incompleto & 2 & 3,45 & 1 & 1,72 \\
Ensino Médio completo & 17 & 29,31 & 18 & 31,04 \\
Superior incompleto & 7 & 12,07 & 2 & 3,45 \\
Superior completo ou mais & 13 & 22,41 & 13 & 22,41 \\
Não sabe responder & 0 & 0 & 1 & 1,72 \\
TOTAL & $\mathbf{5 8}$ & $\mathbf{1 0 0}$ & $\mathbf{5 8}$ & $\mathbf{1 0 0}$
\end{tabular}

Fonte: Autores. 
A tabela 2 traz os dados que a maioria das mães $(29,31 \%)$ e dos pais (31,04\%) possuem ensino médio completo. Esses dados são melhores do que os dados da pesquisa da UNESCO (2004), na qual quase $50 \%$ dos entrevistados possuíam pais com ensino fundamental incompleto. Nota-se que, curiosamente, na nossa pesquisa, o próximo nível de escolaridade mais presente é o ensino fundamental incompleto $(20,69 \%$ das mães e $22,41 \%$ dos pais) praticamente empatado com o outro extremo - Superior completo ou mais $(22,41 \%$ para mães e o mesmo valor para pais). Esses dados refletem tanto uma mobilidade social entre os atuais docentes, como também uma continuação da escolaridade familiar direta.

TABELA 3 - Proporção de professores, segundo nível de satisfação com a remuneração recebida no serviço público federal, bem como a comparação com instituições privadas

\begin{tabular}{|c|c|c|c|c|}
\hline \multirow[t]{2}{*}{ Nível de Satisfação } & \multicolumn{2}{|c|}{$\begin{array}{l}\text { Serviço } \\
\text { público } \\
\text { federal }\end{array}$} & \multicolumn{2}{|c|}{$\begin{array}{c}\text { Comparação } \\
\text { com as } \\
\text { instituições } \\
\text { privadas }\end{array}$} \\
\hline & $\mathbf{n}$ & $\%$ & $\mathbf{n}$ & $\%$ \\
\hline Completamente satisfeito & 1 & 1,72 & 10 & 17,24 \\
\hline Satisfeito & 35 & 60,35 & 33 & 56,90 \\
\hline Indiferente & 4 & 6,90 & 6 & 10,35 \\
\hline Insatisfeito & 16 & 27,59 & 8 & 13,79 \\
\hline Completamente insatisfeito & 1 & 1,72 & 0 & 0 \\
\hline Não respondeu & 1 & 1,72 & 1 & 1,72 \\
\hline TOTAL & 58 & 100 & 58 & 100 \\
\hline
\end{tabular}

Fonte: Autores.

A tabela 3 demonstra o nível de satisfação com a remuneração recebida no serviço público e indica que $60,35 \%(n=35)$ estão satisfeitos seguido de $27,59 \%(n=16)$ de insatisfeitos. Em comparação com a remuneração paga em instituições privadas, os docentes completamente satisfeitos $(17,24 \%)$ e os satisfeitos $(56,90 \%)$ somam $74,14 \%$. 


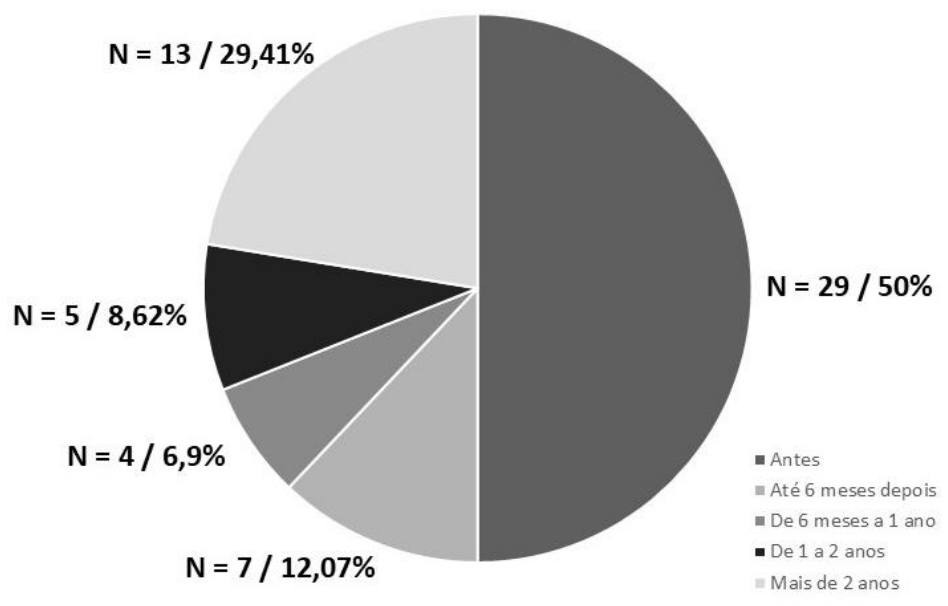

Figura 4 - Tempo em que conseguiu o primeiro emprego como docente, tendo como marco a obtenção do diploma de graduação.

Fonte: Autores

Ao analisar os dados sobre o início da carreira docente, conforme revela a Figura 4, observa-se que tende a começar cedo, antes da obtenção do diploma de graduação. De acordo com os dados obtidos, $50 \%(n=29)$ dos docentes obtiveram o primeiro emprego como docente antes da conclusão da graduação. Outros $29,41 \%(n=13)$ relataram que ingressaram no mercado de trabalho docente antes de completar 6 meses de formados.

De acordo com a natureza dos cursos ofertados e da atuação da instituição com tradição em oferta de cursos técnicos, muitos docentes são oriundos do mundo técnico do trabalho de industrias e demais segmentos e não apenas da carreira das tradicionais licenciaturas. Desse modo, apenas $58,62 \%(n=34)$ dos professores pesquisados são licenciados. O IFBA estimula e promove regularmente a formação em complementação pedagógica para os docentes não licenciados e a meta é que todos os docentes possuam licenciatura ou formação em complementação pedagógica.

Do total de docentes entrevistados, $6,90 \%(n=4)$, possuem licenciatura e bacharelado na mesma área de formação e outros 8 docentes $(13,8 \%)$ possuem segunda graduação em outros cursos/áreas.

Com relação às pós graduações, $65,52 \%(n=38)$ possuem especialização, e, destes, $23,67 \%$ possuem 2 especializações concluídas. Um total de $79,31 \%(n=46)$ dos docentes possuem mestrado concluído, $6,90 \%(n=4)$ possuem mestrado em andamento e $1,72 \%(n=1)$ possui 2 mestrados concluídos. Com relação ao doutorado, $22,41 \%(n=13)$ possuem o título de doutor e 10,35\% $(n=6)$ estão cursando esse tipo de pós graduação. Apenas $5,17 \%(n=3)$ dos docentes possuem a graduação como titulação máxima.

A Figura 5 mostra a titulação máxima dos docentes no campus pesquisado, onde se observa que apenas $5,17 \%(n=3)$ possuem titulação 
máxima como graduação, 15,51\% ( $n=9)$ como especialização, 56,90\% ( $\mathrm{n}=$ 33) são mestres e $22,41 \%(n=13)$ doutores como titulação máxima.

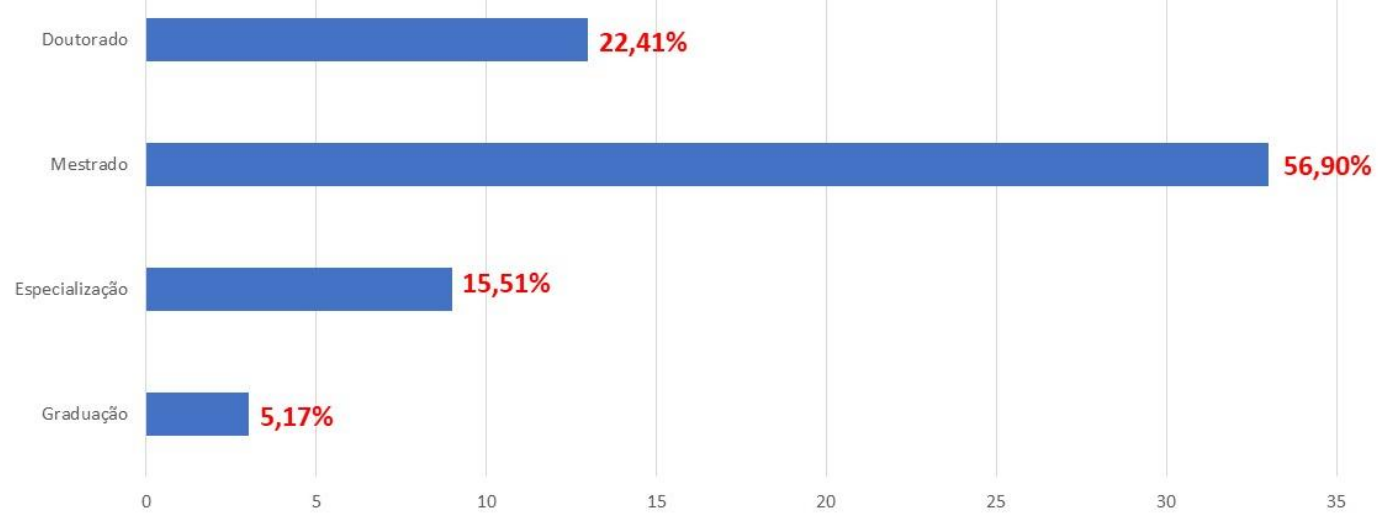

Figura 5 - Titulação máxima dos docentes do campus do IFBA sob estudo.

Fonte: Autores

\subsection{FORMAÇÃO DOCENTE, TEMPO DE DOCÊNCIA, DESLOCAMENTO PARA O CAMPUS}

Cerca de $63,79 \%(n=37)$ dos docentes possuem experiência na área técnica de trabalho (exceto docência). Essa fato é importante, visto que possuem uma visão com mais experiência no mundo do trabalho, ajudando no processo de ensino e aprendizagem. Esse alto percentual é ajudado pelas áreas dos cursos da instituição pesquisada, que incluem engenheiros diversos e profissionais de informática, geralmente cursos de bacharelado e tecnológicos, voltados para a inserção nas respectivas áreas técnicas no mundo do trabalho.

A maioria dos docentes entrevistados, de acordo com a Tabela 4, possui entre 6 e 10 anos de docência com 27,59\% $(n=16)$, seguidos pela categoria seguinte, 11 a 15 anos de docência com 25,86\% ( $n=15)$. Esses números estão proporcionalmente em sintonia com os dados da UNESCO (2004).

A maior parte dos docentes, 58,62\% ( $n=34)$, possui ensino superior com formação pedagógica. Porém, ainda é alto o nível de docentes sem licenciatura, considerando que o prazo para que todos os docentes da educação básica tenham licenciatura na área de conhecimento finda em 2020. Todos os docentes possuem ensino superior completo. (NICOLIELO, 2018).

Outro dado que merece destaque na Tabela 4 é que maioria dos docentes sem formação pedagógica possuem entre 11 e 15 anos de docência. O IFBA tem se mobilizado para resolver essa situação promovendo parcerias para ofertar cursos de formação pedagógica de $1100 \mathrm{~h}$ para 
docentes sem licenciatura para resolver essa situação, de acordo com a Meta 15 do Plano Nacional da Educação - PNE 2014-2024 (BRASIL, 2014). O Instituto possuia na época da coleta de dados dessa pesquisa 1338 docentes, sendo que $52,24 \%(n=699)$ não possuem a formação pedagógica. Dessa forma, o campus possui proporcionalmente menos docentes sem licenciatura do que a instituição como um todo (MORADILLO, 2018).

TABELA 4 - Proporção de professores, por habilitação, segundo o tempo de docência

\begin{tabular}{ccccccc}
\multicolumn{7}{c}{ Habilitação } \\
Tempo de Docência & $\begin{array}{c}\text { Ensino } \\
\text { Superior com } \\
\text { formação } \\
\text { pedagógica } \\
\text { (Licenciatura) }\end{array}$ & $\begin{array}{c}\text { Ensino } \\
\text { Superior sem } \\
\text { formação } \\
\text { pedagógica }\end{array}$ & Total \\
& $\mathbf{n}$ & $\%$ & $\mathbf{n}$ & $\%$ & $\mathbf{n}$ & $\%$ \\
Até 5 anos & 1 & 1,72 & 4 & 6,90 & 5 & 8,62 \\
De 6 a 10 anos & 8 & 13,79 & 8 & 13,79 & 16 & 27,59 \\
De 11 a 15 anos & 6 & 10,35 & 9 & 15,52 & 15 & 25,86 \\
De 16 a 20 anos & 10 & 17,24 & 3 & 5,17 & 13 & 22,41 \\
De 21 a 25 anos & 5 & 8,62 & 0 & 0 & 5 & 8,62 \\
Mais de 25 anos & 4 & 6,90 & 0 & 0 & 4 & 6,90 \\
TOTAL & $\mathbf{3 4}$ & $\mathbf{5 8 , 6 2}$ & $\mathbf{2 4}$ & $\mathbf{4 1 , 4 8}$ & $\mathbf{5 8}$ & $\mathbf{1 0 0}$
\end{tabular}

Fonte: Autores.

O referido campus do IFBA possui cursos distribuídos em 4 modalidades de ensino: integrado, subsequente, PROEJA e superior, sendo que $36,2 \%(n=21)$ lecionam em apenas uma modalidade, 46,55\% ( $n=27)$ ensinam em 2 modalidades, 13,8\% $(n=8)$ em 3 modalidades e apenas $3,45 \%(n=2)$ ministram aulas em todas as modalidades, levando em consideração o semestre letivo da entrevista. Esses números podem variar, visto que os docentes, reunidos em suas respectivas áreas, que decidem as disciplinas que cada professor lecionará nos períodos letivos seguintes.

A Figura 6 traz o tempo de exercício dos docentes no campus estudado do IFBA. A maioria dos docentes possui de 9 a 12 anos de docência no instituto com $27,32 \%$. Certamente impulsionado pelo início das atividades do campus em 2006 que contou com concursos públicos para preenchimento das vagas. 


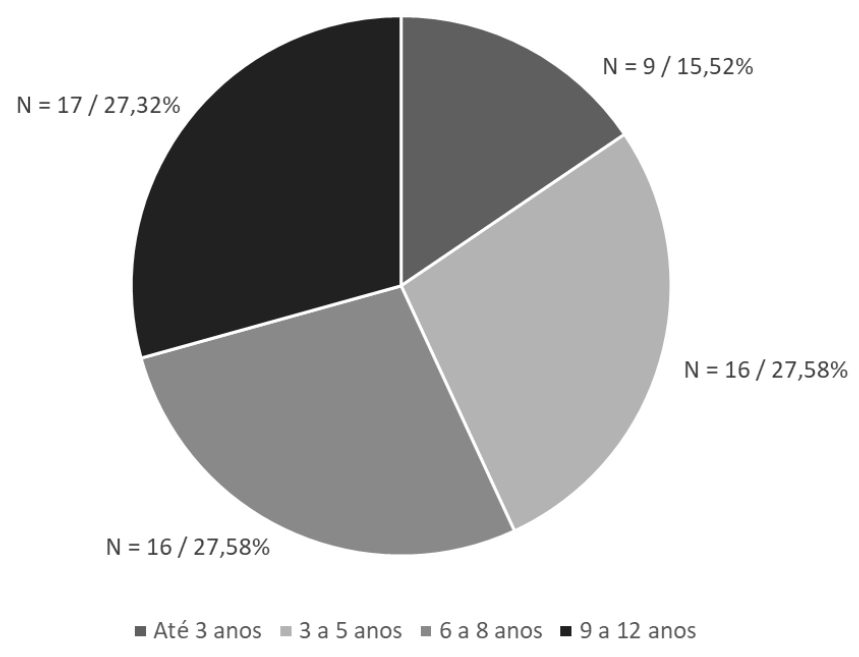

Figura 6 - Tempo de exercício no campus diagnosticado do IFBA

Fonte: Autores

Apenas $10,35 \%(n=7)$ dos docentes foram removidos de outros campi, todos os demais entraram em exercício no IFBA no próprio campus. Talvez esses dados ajudem a explicar o fato de $76,47 \%(n=39)$ dos docentes efetivos desejarem remoção para outros campi, visto que assumiram o cargo público através de concurso público, muitas vezes, longe de seus domicílios. Também deve ser levado em consideração o fato de que no momento das entrevistas $15,67 \%(n=8)$ dos docentes efetivos estavam com remoção aprovada em edital do ano de 2015 para diversos campi, o que tendencia um pouco esses dados. Porém, o número de interessados em remoção ainda assim é alto. As justificativas para a remoção foram diversas, entre as mais frequentes figuram a questão de trabalhar mais perto da residência, de trabalhar e morar mais perto de familiares e a distância do deslocamento da residência.

Essa discussão vai ao encontro dos dados em que $36,21 \%(n=21)$ alugam casa na cidade com amigos, por não considerarem a cidade do campus analisado como domicílio e $41,38 \%(n=24)$ não pernoitam na cidade, sempre indo trabalhar e retornando para seus lares em outras cidades. Apenas um docente $(1,72 \%)$ relatou morar na mesma cidade do campus. Outros ainda alugam casas individualmente $3,45 \%(n=2)$, ficam hospedados em casas de amigos $1,72 \%(n=1)$ ou preferem pernoitar em hotéis e pousadas $15,52 \%(n=9)$.

Outros dados (Figura 7) que ainda conversam com a questão do alto número de professores que desejam a remoção certamente é o deslocamento para o instituto, visto que a quase totalidade não mora na cidade e este motivo foi um dos mais citados como motivador para o desejo de remoção. 


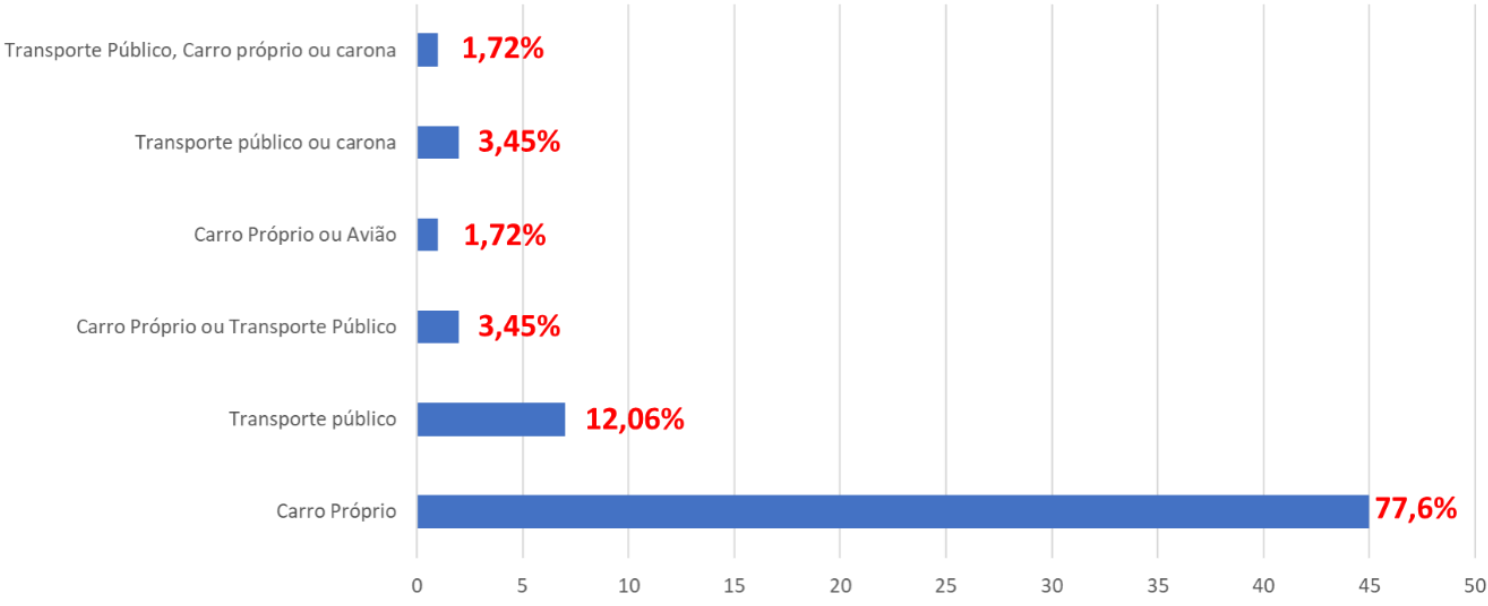

Figura 7 - Forma de deslocamento dos docentes para o campus do IFBA sob estudo.

Fonte: Autores

Nota-se na Figura 7 que a grande maioria dos docentes utilizam carro próprio para deslocamento ao instituto com 77,6\% $(n=45)$, seguido de transporte público com 12,06\% $(n=7)$. O docente que respondeu carro próprio ou avião possui como domicílio o local onde sua família mora em uma cidade em outro estado brasileiro localizada a 1900 quilômetros do instituto fazendo semanalmente essa viagem para poder desfrutar do convívio com seu seio familiar. Desse modo, $82,75 \%(n=48)$, levam entre 1 e 2 horas para se deslocar diariamente para suas atividades rotineiras no campus.

\section{CONSIDERAÇÕES FINAIS}

O Campus do IFBA diagnosticado possui um perfil de professores muito heterogêneo. Nota-se que em alguns aspectos como faixa etária, estado civil, professores homens como chefe de família, membros da família com a profissão de professor e tempo de docência, as características docentes são muito próximas com as do estudo similar realizado pela UNESCO em 2004 que pesquisou 5.000 docentes e que serviu de motivação e referencial para esse estudo. Já em outros aspectos como gênero prevalente, concordância da abordagem de religião na escola e escolaridade dos pais, o perfil docente do campus se afasta muito desse perfil nacional. A natureza de cursos ofertados ajuda no perfil docente do campus, visto que estão mais voltados para a educação profissional e tecnológica do que apenas para a educação básica regular.

O alto índice de docentes com dedicação exclusiva está diretamente relacionado à quantidade de atividades de pesquisa e extensão, além de publicações registrados na instituição.

A baixa quantidade de docentes naturais do Recôncavo Baiano e a inexistência de docentes da cidade onde está localizado o campus pode ser 
um indicador da possível falta/baixa sensação de pertencimento dos docentes ao campus, visto que não possuem naturalidade ou vínculo pessoal na região e cidade.

A laicidade do Brasil é claramente revelada quando percebe-se que 7 religiões foram citadas no universo de 58 professores pesquisados, dos quais, apenas um total de 35 possuem alguma religião. A maioria católica era plenamente esperada, visto que no Brasil após o séc $X V I$ teve uma colonização portuguesa que tinha grande influência da Igreja Católica na Idade Moderna. É pertinente a observação que, por mais que a maioria dos docentes sejam católicos, $63 \%$ dos que se autodeclararam dessa religião não são praticantes. Já todos os espíritas são praticantes, bem como a grande maioria dos docentes de religiões não católicas, quando apenas um docente protestante não é praticante. Esses dados demonstram a tradição católica herdada com as gerações, no entanto sem fazer parte do cotidiano docente.

A religiosidade se coloca como um desafio para as escolas, no que concerne o direcionamento de reflexões docentes sobre sua espiritualidade e sua responsabilidade social no contexto educacional, principalmente de modo coerente em que nenhuma religião possui a verdade absoluta em detrimento das outras e que todas devem conviver harmonicamente com as diferenças presentes no âmbito religioso. Exceto apenas escolas que já possuem alguma doutrinação em sua filosofia de existência, como escolas católicas, adventistas, batistas, entre outras, nas quais é o docente que geralmente interpreta a cultura da escola para o aluno.

A maioria dos docentes possui inspiração da carreira na própria família e apesar de ser expressiva a quantidade de pais e mães dos docentes com ensino superior, é notável o quantitativo de genitores que só cursaram até o ensino médio. Certamente os filhos docentes, então participantes dessa pesquisa, são motivo de orgulho com relação aos estudos em seus ambientes familiares. Outro dado que chama atenção é que cerca de $50 \%$ dos docentes conseguiram o primeiro emprego como professor antes da conclusão da graduação.

O emprego como professor na rede federal de ensino propicia e estimula o estudo e produção acadêmica e científica por meio de ações de ensino, pesquisa e extensão. A alta titulação dos docentes do referido campus demonstram este viés.

Um dado que merece destaque e que o campus e o instituto podem olhar com mais atenção é que grande parte dos docentes não possuem formação pedagógica, o que se explica pela natureza de cursos ofertados que exigem formação em áreas técnicas. Isso pode ser um alerta para que o IFBA promova mais cursos de complementação pedagógica.

Uma grande parte dos docentes pesquisados desejavam remoções para outros campi do instituto, por motivos diversos como, qualidade de vida e trabalhar mais perto da família. Nesse aspecto, a gestão do instituto poderia realizar com mais periodicidade editais de remoção para verificar possíveis ajustes que atendessem às remoções pretendidas sem prejudicar 0 andamento e atividades dos campi, bem como transcorrendo com lisura e democracia nos processos de remoção. 
A continuação da pesquisa e o diagnóstico detalhado sobre quem são os professores são fatores de fundamental relevância para que se possam tomar medidas efetivas voltadas à sua valorização, sobretudo no Brasil, um país onde a educação possui absoluta importância na formação da cidadania dos jovens. O perfil dos docentes, no que tange suas características socioeconômicas, condições profissionais, percepções, cultural dentre outras, baliza o processo de ensino-aprendizagem e de referência dentro e fora da sala de aula.

\section{REFERÊNCIAS}

AZEVEDO, Guilhermo. Laicidade estatal e a obrigatoriedade de oferecimento de Ensino Religioso nas escolas públicas do Brasil. Jus Brasil, 2016.

BORGES, Moema; SANTOS, Marília; PINHEIRO, Thiago. Representações sociais sobre religião e espiritualidade. Revista Brasileira de Enfermagem. 2015, jul-ago, 68(4), p. 609-16.

BRASIL. Constituição (1988). Constituição da República Federativa do Brasil. Brasília, DF: Senado Federal: Centro Gráfico, 1988. 292 p.

BRASIL, Ministério da Educação. Lei no 9.394, de 20 de dezembro de 1996. Estabelece as diretrizes e bases da educação nacional. Brasília/DF, 23/12/1996, p. 27833. Disponível em <http://www.planalto.gov.br/ccivil_03/LEIS/I9394.htm>, Acesso em: 10/07/2019.

BRASIL, Ministério da Educação. Lei n 13.005 de 25 de junho de 2014. Aprova o Plano Nacional de Educação - PNE e dá outras providências. Brasília/DF, 26/06/2019, Edição Extra, p. 1. Disponível em < http://www.planalto.gov.br/ccivil_03/_ato2011-2014/2014/lei/l13005.htm>, Acesso em: 13/08/2019.

BRASIL, Ministério da Educação. Nota técnica 50/2016/CGDP/DDR/SETEC/SETEC. 2016. Disponível em <http://portal.mec.gov.br/index.php?option=com_docman\&view=download\&ali as=36941-nota-tecnica-n50-2016-calculo-contracao-professor-substitutopdf\&category_slug=abril-2016\&ltemid=30192> Acesso em: 22/04/2019.

FERREIRA, Aurélio Buarque de Holanda. Dicionário Aurélio da Língua Portuguesa. 5a ed, Curitiba: Positivo, 2010. 
IBGE, Censo 2010: número de católicos cai e aumenta o de evangélicos, espíritas e sem religião. 2012. Disponível em

$<$ https://agenciadenoticias.ibge.gov.br/agencia-noticias/2013-agencia-denoticias/releases/14244-asi-censo-2010-numero-de-catolicos-cai-e-aumentao-de-evangelicos-espiritas-e-sem-religiao.html>, Acesso em: 22/04/2019.

GATTI, B. A. Formação continuada de professores: a questão psicossocial. Cad. Pesquisa. [online]. 2003, n.119, p.191-204. Disponível em $<$ http://www.scielo.br/scielo.php?script=sci_arttext\&pid=S0100157420030002 00010\& Ing=pt\&nrm=isso>. Acesso em 13/06/2019.

GOODSON, I. F. Dar voz ao professor: as histórias de vida dos professores e o seu desenvolvimento profissional. In: NÓVOA, A. (Org.). Vidas de professores. 2. ed. Porto: Porto Editora, 1995. p. 63-77

GOULART, Michel. História Digital - Atividade: Mapas em branco para preencher. 2014. Disponível em <http://www.historiadigital.org/atividades/atividade-mapas-em-branco-parapreencher/> Acesso em: 16/01/2019.

HOUAISS, Antônio; VILLAR, Mauro de Salles. Dicionário Houaiss da Língua Portuguesa. 1a ed. Rio de Janeiro: Objetiva, 2009.

MAK, Denise. A presença da religião em uma escola pública de educação infantil. Dissertação (Mestrado em Educação: História, Política e Sociedade) - Pontifícia Universidade Católica de São Paulo. São Paulo, p. 96. 2014

MEC/INEP, Estudo exploratório sobre o professor brasileiro com base nos resultados do Censo Escolar da Educação Básica 2007. Instituto Nacional de Estudos e Pesquisas Educacionais Anísio Teixeira. - Brasília : Inep, 2009.

MORADILLO, lali. Curso de formação pedagógica para professores não licenciados. Instituto Federal da Bahia. 2018. Disponível em $<$ https://portal.ifba.edu.br/instituto-federal/noticias-2018/curso-de-formacaopedagogica-para-professores-nao-licenciados>, Acesso em: 02/04/2019

NICOLIELO, Bruna. Magistério: 2020 é o prazo final. Nova Escola. 2018. Disponível em <https://novaescola.org.br/conteudo/150/magisterio-2020prazo-final>, Acesso em: 02/04/2019. 
NÓVOA, A. Os professores na virada do milênio: do excesso dos discursos à pobreza das práticas. Educação e Pesquisa, São Paulo, v. 25, n. 1, p. 11-20, jan./jun. 1999.

SANTOS, Silvana Fortaleza. Perfil do professor de Ensino Religioso da Educação Infantil e Anos Iniciais. Revista Lusófona de Ciência das Religiões, Ano VI, 2007, n.ำ12, p. 149-157.

SAMPAIO, Dulce Moreira. A Pedagogia do Ser: educação dos sentimentos e dos valores humanos. Petrópolis, RJ: Vozes, 2004.

SEABRA, R. D.; MATTEDI, A. P. Levantamento do Perfil de Estudantes Ingressantes nos Cursos de Computação da Universidade Federal de Itajubá: Um estudo socioeconômico e cultural. Revista de Sistemas e Computação, Salvador, v. 7, n. 1, p. 44-58, jan./jun. 2017.

SILVA, Maria Eliane Azevedo da; SOARES, Afonso Maria Ligório. Formação docente e o Ensino Religioso: resultado preliminar de levantamento sobre teses e dissertações no Brasil. Revista Pistis Prax., Teol. Pastor., Curitiba, v. 2, n. 2, p. 361-381, jul./dez. 2010

SOUZA, A. R. de. O professor da educação básica no Brasil: identidade e trabalho. Educar em Revista, Curitiba, Brasil, n. 48, p. 53-74, abr./jun. 2013. Editora UFPR

UNESCO. O Perfil dos professores brasileiros: o que fazem, o que pensam, o que almejam - / Pesquisa Nacional UNESCO, - São Paulo : Moderna, 2004. Disponível em:

<http://unesdoc.unesco.org/images/0013/001349/134925por.pdf.>, Acesso em 15/09/2018.

VALENTE, Gabriela. Pluralidade religiosa e religião no ambiente escolar. In: GHANEM, Elie; NEIRA, Marcos Garcia (Org.). Educação e diversidade cultural no Brasil: ensaios e práticas. Araraquara: Junqueira e Marin, 2014. p. 79-99.

VIEIRA, Marili; PLACCO, Vera Maria. A dimensão da espiritualidade no processo de constituição identitária do professor. Revista da FAEEBA Educação e Contemporaneidade, Salvador, v. 20, n. 35, p. 1-242, jan/jun. 2011. 